\title{
Gossypiboma of the Abdomen and Pelvis; A Recurring Error
}

\author{
Gilbert Maranya $^{1,2}$, Heltam Maganga $^{1}$, Bernard Mwero $^{1,2}$
}

1. Coast Province General Hospital, Mombasa, Kenya

2. Moi Hospital, Voi, Kenya

Correspondence to: Dr. Gilbert Maranya, P.0 Box 91066-80103 Mombasa, Kenya. Email: gilbertmaranya@gmail.com

\begin{abstract}
Introduction: Gossypiboma is a retained surgical sponge commonly in the abdomen and pelvis. Risk factors include emergency and prolonged surgery. Attendant complications are: visceral obstruction, perforation, sepsis, fistulae and diagnostic dilemmas. The objective of this write up is to report the occurrence of gossypiboma and recommend corrective measures. Methods: A retrospective audit undertaken at two hospitals in the Coast region of Kenya between 2008 and 2016 involved 11 patients. Results: A female preponderance of $73 \%$ was observed. The mean age was 32 years. Emergency surgery accounted for $73 \%$ of the patients; with caesarian section dominating. Most patients were operated upon; while in one patient with uterine cervical tear and episiotomy, the
\end{abstract}

\section{Introduction}

Gossypiboma is a retained surgical sponge. It is a rare but ubiquitous medical error (1-3). There is reluctance to publish this matter for fear of medico legal implications, and criticism by the public and medical profession (4-6). Gossypiboma usually occurs in the abdominal and pelvic cavities (7). The risk for gossypiboma is higher in emergencies, prolonged surgery, operations entailing more than one major procedure, more than one surgical team, failure of surgical or incorrect counts, unexpected intraoperative factors and high intraoperative blood loss (2, 7-9).

Presentation is variable from immediate to late, with some sponges remaining asymptomatic (4). Sequels of gossypiboma are: sepsis, visceral perforation, penetration, obstruction, fistulae formation, intraluminal migration and death $(3,7)$. It may also present as a mass mimicking a tumor or tumor recurrence. Gossypiboma increases medical costs through investigations, surgical procedures sponge was extruded spontaneously per vaginum. One caesarian section patient had two sponges. In another two caesarian section patients, the sponges had no radiopaque marker. Mortality occurred in $3(27 \%)$ patients. Conclusion: The incidence of gossypiboma can be minimized by proper gauze and instrument management intraoperatvely. Change of operating personnel during surgery is discouraged.

Key words: Gossypiboma, Retained surgical sponges, Textilloma

Ann Afr Surg. 2017;14(1): 44-47.

DOI: http://dx.doi.org/10.4314/aas.v14i1.9

(C) 2017 Annals of African Surgery. This work is licensed under the Creative Commons Attribution 4.0 International License.

and morbidity (1). Radiological investigations have high diagnostic value and comprise ultrasonography, plain abdominal radiography and computerized tomography scanning $(7,10)$.

Gossypiboma may be prevented by counting sponges before and after surgery, use of sponges with radiopaque markers, tagging sponges and compresses used in the abdomen, adequate examination of the operative field and radiography of the abdomen before wound closure if required $(1,10-12)$. Retained sponges still occur despite a presumed correct swab count (3). We undertook a study of the occurrence of abdominal and pelvic gossypiboma at two hospitals .

\section{Methods}

This retrospective audit involved 11 patients over a 9-year period between 2008 and 2016. Ten patients were from Coast Province General Hospital, Mombasa, which is a referral hospital for the Coast region of Kenya. It has a bed capacity of 700. One patient was from Moi 
Hospital, Voi, a referral hospital for Taita Taveta County in the Coast region of Kenya. It has a bed capacity of 130. Patient records were retrieved and analyzed. Patient demographics, details of initial diagnosis and surgery were extracted. Record was made of clinical presentation, examination, investigation, interval to and subsequent surgery and outcome. Institutions of referred patients were informed of the diagnosis after surgery.

\section{Results}

The ages of the patients ranged from 18 to 48 years with a mean of 32 years. The male to female ratio was 3: 8. The interval between the initial operation and surgery for the retained sponge ranged from 1 week to 12 years with a median time of 2 months. The most common symptoms are tabulated in Table 1

Most of the patients were referred from other institutions; so we could not establish operative swab counts.

Caesarian section was the most common operation associated with retained sponges. At laparotomy for sponge removal one of the caesarian section patients had 2 sponges; an abdominal pack and a gauze that penetrated the small bowel. In two other caesarian section patients the sponges had no radiopaque marker. One of these patients had sickle cell disease and the retained pack was initially incorrectly reported as splenomegaly on ultrasonography. The radiological investigations and sponge in this patient are shown in Figure 1 . The details of the operations that resulted in retained sponges are in Table 1.

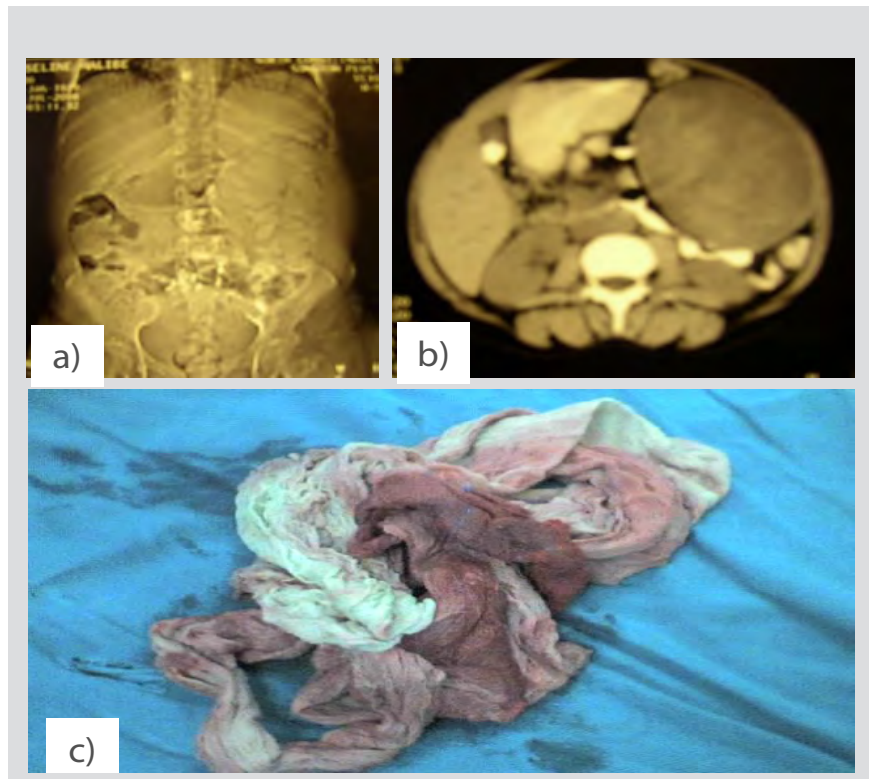

Figure 1: Gossypiboma in a 29 year old female sickler after caesarian section. a) Plain abdominal radiograph; no radiopaque marker. b) Computerized tomography scan of abdomen; sponge mass was mistaken for splenomegaly. c) The retained abdominal pack.
An 18 year old male patient who had pelvic surgery 12 years earlier manifested with fever, right hydronephrosis, left pyonephrosis, bilateral renal calculi and a contracted urinary bladder. He underwent sponge extraction, urinary bladder release and left nephrectomy. His radiological investigations and the operative specimens are shown in Figure 2. Another patient previously managed for uterine cervical tears spontaneously extruded the retained sponge per vaginum 4 months later.

All referred patients were managed by a consultant surgeon. The patient with retained sponge after appendectomy underwent surgery by the same medical officer; as the preoperative diagnosis was abscess formation.

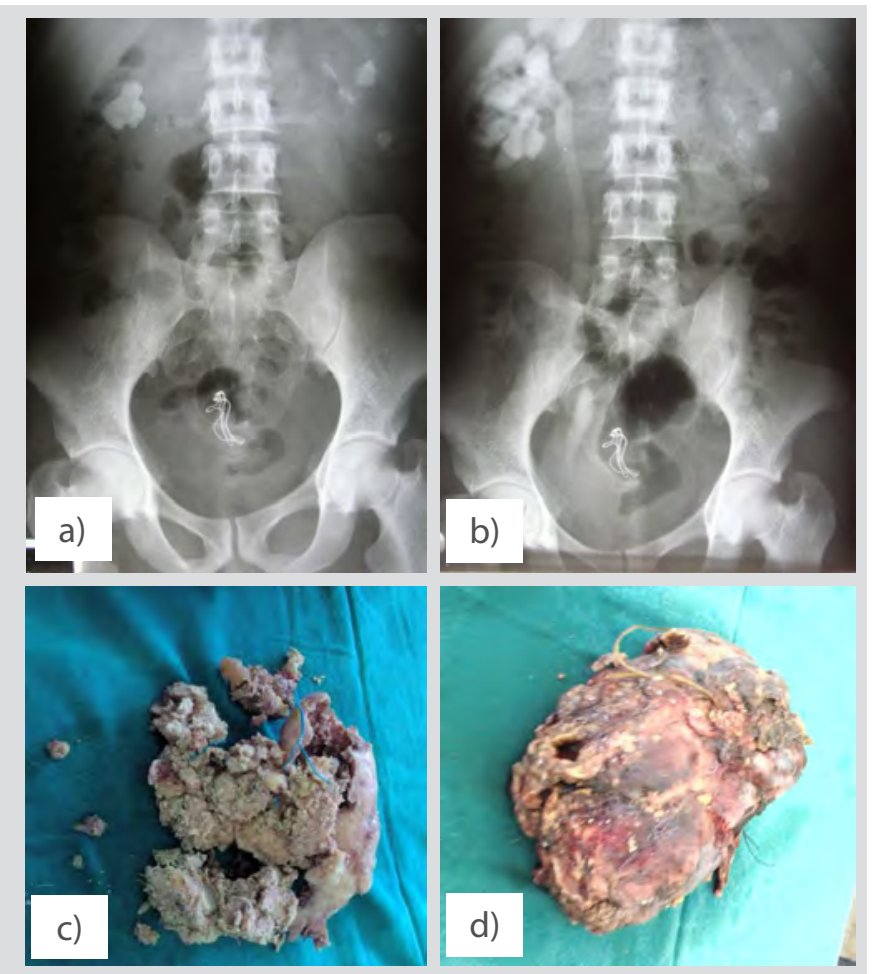

Figure 2: Pelvic gossypiboma in an 18 year old male of 12 years duration. a) Plain abdominal radiograph. b) Excretory urogram. c) The encrusted retained sponge. d) Left nephrectomy specimen.

The outcome of reoperation, sponge extraction and the sponge extrusion was satisfactory in 8 patients. Death occurred in 3 patients. One patient who presented with intestinal obstruction after caesarian section developed low output enterocutaneous fistulae after laparotomy to remove the retained sponge. No bowel resection was done. She was on treatment for HIV and anemia. She was ambulant and feeding normally. She collapsed and died a week later while in the toilet and no autopsy was conducted for religious reasons..

The second patient had been referred with intestinal obstruction after abdominal hysterectomy for uterine fibroids. She developed low output enterocutaneous

45 The ANNALS of AFRICAN SURGERY. January 2017 Volume 14 Issue 1 
fistulae after adhesiolysis. She was ambulant and feeding normally. She collapsed and died on the fifth day postoperatively on the way to the toilet and no autopsy was conducted for religious reasons.

Death of the third patient was due to metastases from carcinoma of the urinary bladder.

Table 1: Characteristics of 11 patients with abdominal and pelvic gossypiboma.

\begin{tabular}{|c|c|}
\hline Age/years & Range 18 - 48. M ean 32. \\
\hline Gender & M ale: 3, Female: 8. \\
\hline Type of initial surgery & $\begin{array}{l}\text { E mergency: } 8 \text {. Caesarian } \\
\text { section } 4 \text {, ruptured ectopic } \\
1 \text {, uterine cervical tears } 1 \text {, } \\
\text { appendectomy } 1 \text { (female), } \\
\text { blunt abdominal trauma } 1 \\
\text { (male). } \\
\text { Elective: } 3 . \text { A bdominal } \\
\text { hysterectomy } 1 \text {, radical } \\
\text { cystectomy } 1 \text { (male), pelvic } \\
\text { surgery } 1 \text { (male). }\end{array}$ \\
\hline Clinical presentation & $\begin{array}{l}\text { A bdominal mass } 2 \text {, intestinal } \\
\text { obstruction } 3 \text {, abscess } \\
3 \text {, sinuses } 1 \text {, incisional } \\
\text { hernia } 1 \text {, upper urinary } \\
\text { tract obstruction } 1 \text {, low er } \\
\text { urinary tract symptoms } 1 \text {, } \\
\text { pyohydronephrosis } 1 \text {, vaginal } \\
\text { discomfort and bleeding } 1 \text {. }\end{array}$ \\
\hline $\begin{array}{l}\text { Outcome: surgery } 10 \text {, } \\
\text { spontaneous extrusion } \\
1\end{array}$ & $\begin{array}{l}\text { Satisfactory: } 8 . \\
\text { Death: } 3 . \\
\text { - Caesarian section; } \\
\text { intestinal obstruction, } \\
\text { enterocutaneous fistulae. } \\
\text { Probable venous } \\
\text { thromboembolism. } \\
\text { - A bdominal hysterectomy; } \\
\text { intestinal obstruction, } \\
\text { enterocutaneous } \\
\text { fistulae. Likely venous } \\
\text { thromboembolism. } \\
\text { - Radical cystectomy; } \\
\text { metastatic disease from } \\
\text { carcinoma urinary bladder. }\end{array}$ \\
\hline
\end{tabular}

\section{Discussion}

The age distribution in this audit compares with Yildirim with a range of 25 to 79 and Bani-Hani, 20 to $64(3,4)$. This shows that adults are more susceptible. There was female preponderance in our series similar to what Bani-Hani and Yildirim found in their respective studies $(3,4)$. This is easily explained by the common operations specific to women. This was the case in the series of Yildirim and Bani-Hani where abdominal hysterectomy was the most common operation.

In the current series there was a wide time range of between 1 week and 12 years from the initial surgery to presentation with symptoms of retained sponges. This compares similarly with Yildirim, 3 days to 40 years and Bani-Hani, 2 months to 6 years.

Emergency surgery as the causative operation constituted $73 \%$ of cases. This is similar to Bani-Hani at $64 \%$ and Wang who reported increased risk $(3,7)$. Emergency scenarios may frustrate standard sponge and instrument counts. Since most of our patients were referrals, we could not establish the matter of swab counts. In the study by Bani-Hani (3), a presumed correct swab count was documented in eight patients out of $11(73 \%)$.

The variable clinical presentation in this audit compares well to the studies by Yildirim and Wang $(4,7)$. Most patients in our series were operated on while in one the sponge was extruded per vaginum. This compares with other series where not all patients underwent surgery such as Gawande, and Bani-Hani $(2,3)$ where a sponge was expelled per rectum and another removed cystoscopically.

The mortality in our series of $27 \%$ was high compared with Montasser, 14\%, Gawande, 2\%, Bani-Hani, nil (3), Lincourt and Stawicki, nil (1-3,9,12). Aggressive management of these patients by the relevant specialists will reduce morbidity and mortality.

The only legal challenge was in a patient with ruptured ectopic pregnancy who had been operated at a private hospital. She had bowel resection and anastomosis for intestinal obstruction. The private institution opted to pay all the treatment costs after being informed of the incident. The discrepancy between recorded and actual sponge counts might be due to negligence; where sponge and instrument counts are ticked as correct without verification. Incidents of retained surgical sponges persist despite measures to prevent them. A high index of suspicion is important in reducing this human error with its attendant medical and legal complications for the patient and doctor. Although human errors cannot be eliminated, strict adherence to safety regulations should reduce the incidence of gossypiboma to a minimum (3).

We recommend the application of the World Health Organization Surgical Safety Checklist as this will prevent or minimize the occurrence of gossypiboma.

\section{Conclusion}

The incidence of gossypiboma can be minimized by: sponge counts before and after surgery, tagging all abdominal packs, using sponges with radiopaque markers and taking radiographs before abdominal closure, if warranted. Change of operating personnel during surgery is discouraged. 


\section{Acknowledgement}

We sincerely thank Dr Iqbal Khandwalla, the Chief Administrator, Coast Province General Hospital Mombasa, Kenya for authority to publish this article and Jason Mwawana for the computer work.

\section{References}

1. Montasser AM, Eman T, Edward PM. The Recurring Problem of Retained Swabs and Instruments. Best Pract Res Clin Obstet Gynaecol. 2013; 27: 489-95.

2. Gawande AA, Studdert DM, Orav EJ, et al. Risk factors for Retained Instruments and Sponges after Surgery. N Engl J Med. 2003; 348: 229-35.

3. Bani-Hani KE, Gharaibeh KA, Yaghan RJ. Retained Surgical Sponges (Gossypiboma). Asian J Surg. 2005; 28: 109-15.

4. Yildirim S, Tarim A, Nursal TZ, et al. Retained Surgical Sponge (Gossypiboma) after Intrabdominal or Retroperitoneal Surgery: 14 Cases Treated at a Single Center. Langenbecks Arch Surg. 2006; 391:390-5.

5. MacIntye LK, Jurkovich GJ, Gunn. ML, et al. Gossypiboma: Tales of Lost Sponges and Lessons Learned. Arch Surg. 2010; 145: 770-5.
6. Irabor DO. Underreporting of Gossypiboma in a Third World Country. A Sociocultural View. Niger J Med. 2013; 22: 365-7.

7. Wang CF, Cook CH, Whitmill ML, et al. Risk Factors for Retained Surgical Foreign Bodies: A Metaanalysis. OPUS 12 Scientist. 2009; 3: 21-7.

8. Moffatt-Bruce SD, Cook CH, Steinberg SM, et al. Risk Factors for Retained Surgical Items: A Metaanalysis and Proposed Risk Stratification System. J Surg Res. 2014; 190: 429-36.

9. Lincourt AE, Harrell A, Cristiano J, et al. Retained Foreign Bodies after Surgery. J Surg Res. 2007; 138: 170-4.

10. Vagholkar K, Kharde K. Gossypiboma: A Diagnostic Challenge but a Surgeon's Nightmare. Indian J App Res. 2014; 4: 472-3.

11. Wenshuai $\mathrm{W}$, Thuan L, Loren $\mathrm{R}$ et al. Improving Safety in the Operating Room: A Systematic Literature Review of Retained Surgical Sponges. Current Opin Anaesth. 2009; 22: 207-14.

12. Stawicki SP, Evans DC, Cipolla J, et al. Retained Surgical Foreign Bodies: A Comprehensive Review of Risks and Preventive Strategies. Scand. J. Surg. 2009; 98: 8-17. 